\title{
Entre mediano y pequeño, entre la capilla y el hogar. Consumo privado de escultura menuda en la Sevilla barroca*
}

\author{
Among medium and small, amidst the chapel and the home \\ Private consumption of small sculpture in baroque Seville \\ FERNANDO QUILES \\ Universidad Pablo de Olavide \\ https://orcid.org/0000-0003-0946-3012 \\ fquigar@upo.es
}

\section{RESUMEN}

Aproximación a la demanda de escultura menuda, a mediados del XVII, a partir de los datos extraídos de las fuentes documentales. Se habla del consumo de este tipo de obras que ingresan en el ámbito doméstico como «objetos» de uso diverso, más allá del devocional.

Palabras clave: Barroco sevillano, consumo artístico, escultura ligera, objeto artístico, encargo artístico, siglo XVII

\section{Abstract}

An approach to the demand for small sculpture in the mid-17th century, based on the data extracted from documentary sources. There is talk of the consumption of this type of works that enter the domestic sphere as «objects» of diverse use besides devotional.

Keywords: Sevillian Baroque, artistic consumption, light sculpture, artistic object, artistic commission, 17 th century

Las fuentes documentales abundan en datos sobre demanda artística en el medio sevillano durante el barroco. En el caso de la escultura menuda, generalmente obras de devoción -de Cristo, la Virgen y las diversas manifestaciones de la hagiografía local-, las referencias son muy interesantes porque nos permiten reescribir un capítulo del coleccionsimo artístico que merece atención. Una tarea que puede completarse con el análisis de una parte de las imágenes que se reparten por sacristías, capillas privadas y

\footnotetext{
* Agradezco a los/las evaluadores/as que con su rigurosa revisión del texto, me han permitido realizar una
} sustancial mejora del mismo. 
espacios conventuales, fuera del ámbito doméstico, donde inicialmente estuvieron. ${ }^{1} \mathrm{Me}$ interesa ahora resaltar la importancia de este consumo privado, que prestó especial atención al precio y sobre todo el tamaño de las piezas, que tendió a normalizarse por debajo de la vara de altura. ${ }^{2}$ Ello me lleva a cuestionarme el marco de referencia de los estudios sobre coleccionismo barroco en el medio sevillano, al considerar que en la relación entre cliente y artista se establecieron unos vínculos altamente «significativos» que aún requieren atención. ${ }^{3}$

\section{NO POR MENUDA ES MENOR}

Muy elocuente resulta el testamento del escultor Manuel de Morales, dictado en abril de 1654. Morales, que era de origen portugués y se había formado al lado de Francisco de Ocampo, refiere en este documento que había realizado para el ministril Francisco de Acosta, «qu'es mi vecino», «una hechura de nra señora de la conssep ${ }^{\text {on }}$ de poco más de media bara sin trono». ${ }^{4} \mathrm{Y}$ al racionero «fulano guerrero» le hizo un san Francisco de media vara, que no le llegó a entregar por su fallecimiento. También Pedro Sánchez de Sayas tuvo una obra suya, un san José. Interesante es la referencia al músico ciego, que cantaba sus «salbes», cuyo nombre desconocía («no sé cómo se llama»), con cuyo muerte quedó sin ultimar la talla de el Niño Jesús que le había pedido. ${ }^{5}$ Por su parte, Diego de Ávila le

1 Roda Peña se adentró en el hogar de un rico comerciante portugués, relacionando su posición con los bienes artísticos atesorados. Roda Peña, J. «Los bienes artísticos de Diego de Paiva, un comerciantes portugués en la Sevilla del siglo XVII», Atrio, 13-14, 2007-2008, pp. 127-128.

2 Sin ir más lejos las referencias a la personalidad artística de Cristóbal Ramos, ya en pleno XVIII, quien atendió una importante demanda privada de escultura devocional. Martínez Lara, P. M. y de la Torre Amerighi, I., «Una escultura desconocida de Cristóbal Ramos (1725-1799). Iconografía, uso artístico y mentalidad ilustrada a propósito de una imagen de San José con el Niño», Liño. Revista Anual de Historia del Arte, 23, 2017, pp. 64-65.

3 En este punto cabe al menos la mención a la semiótica y a la personal interpretación de Jean Baudrillart. Un modelo de lectura que, no obstante, dedica a la sociedad contemporánea: La sociedad de consumo. Sus mitos, sus estructuras, Madrid, Siglo XXI, 2009. Por lo que respecta a la percepción global del consumo, recomiendo varias lecturas: McKendrick, Neil et al., The Birth of a Consumer Society, Londres, 1982; Brewer, John, Poter, Roy, Consumption and the World of Goods, Abingdom, Routledge, 1993; De Vries, Jan, The Industrious Revolution, Consumer Behavior and the household Economy 1650 to the Present, Cambridge, Cambridge University Press, 2008; Trentman, Frank, ed., The Oxford Handbook of the History of Consumption, Oxford-New York, Oxford University Press, 2012; Yun Casalilla, Bartolomé, Aram, Bethany, Global goods and the Spanish Empire, 1492-1824: circulation, resistance and diversity Houndmills, Palgrave Macmillan, 2014. Agradezco a mis compañeros de Departamento, Bartolomé Yun y Omar Svriz Wucherer, su apoyo en la inmersión en esta corriente historiográfica.

4 No la pudo acabar por la enfermedad, pero «si su dueño la quisiere llebarse en el estado que esta que se le dé». Archivo Histórico Provincial de Sevilla (en adelante. AHPS), 12938, fols. 105-106; 20-IV-1654.

$5 \quad$ No me resisto a conectar con la idea que desarrollan algunos especialistas sobre el lugar que en la sociedad de antiguo régimen jugaron algunos ciegos, considerados incluso mediadores culturales. Valga el texto de Iglesias Castellano, A., «El ciego callejero en la España Moderna: balance y propuestas», LaborHistórico, 2/1, 2016, pp. 74-90. 
«mandó hacer vna hechura de un san diego de media bara sin peaña y otra de sr san $\mathrm{Ju}^{\circ}$ con su Peaña». ${ }^{6}$ Y además se estableció una salvaguarda legal, por la que, aun cuando «les falta poco para acabar[,] $\mathrm{m}^{\text {do }}$ que si yo falleciere la dha mi mujer las a de acabar y cobre». ${ }^{7}$

No se pierda de vista tampoco que los frustrados intentos del artífice por cumplir con lo pactado, hubieron de estar relacionados con la peste -la del 49-, que tan pernicioso efecto tuvo sobre la producción artística sevillana. ${ }^{8}$

Por lo que respecta a las relaciones entre clientes y artistas, aun cuando sigo acumulando más dudas que certezas, las sitúo en el punto en el que lo habitual, entre quienes disponían de medios económicos, era que se guiasen más por 'querencias votivas' que por criterios artísticos, sin descartar incluso el gusto por las rarezas. Con esta última referencia aludo a las curiosidades de Indias, que también ingresaron en algunos hogares sevillanos ${ }^{9}$. Son detalles que retratan a un colectivo no precisamente cultivado, actuando por emulación y adquiriendo a veces objetos que no precisamente manifestaban un criterio más acumulativo que coleccionista, propio de individuos cuyos hogares tuvieron puerta abierta al Arenal. ${ }^{10}$ Una vía por la que fluyeron incluso las imágenes de devoción, como el «retrato de nra Señora del mar», estampa en vitela, que perteneció a don Duarte de Morales, hermano del capitán Diego de Morales. Suyo fue también un «sto xpto de las caydas», así como «una gabetilla de diferentes reliquias y un santo xpto cruçificado pequeño de bronçe». ${ }^{11}$

Tal como evidencias las fuentes, algunas de estas piezas quedaron fuera del oratorio, sea el estrado como las alcobas, como el Niño Jesús que el comerciante vasco Nicolás de Aroça y Ugalde había colocado sobre un contadorcito. ${ }^{12}$ Con ello verificamos la versatilidad de algunas piezas que, sin perder su función sacralizadora del espacio privado, también tuvieron un uso decorativo.

Estas obras se vendían en tienda, donde el cliente disponía de existencias («en stock»), sin que mediara acuerdo contractual. Es así como el beneficiado de san Andrés, Lorenzo Maldonado y Zúñiga, se hizo con «vna hechura de un niño Jesus de madera[:]

6 AHPS, 12938, fol. 105vto-6r; 20-IV-1654.

7 Idem, 106r.

8 De ello me he ocupado en diversos trabajos, del que destaco «Abril para morircolecciones artísticas sevillanas en el año de la peste (1649) », In López Calderón, C., Fernández Valles, Mª de los y Rodríguez Moya, I., coords., Barroco iberoamericano: Identidades de un imperio, Santiago de Compostela, Andavira, 2013, vol. 2, pp. 257-273.

9 En los propios asientos notariales figura el término rarezas de Indias. Quiles, F. Sevilla y América en el Barroco. Comercio, ciudad y arte, Sevilla, Bosque de Palabras, 2009, p. 84.

10 De ellos me he ocupado en diversas ocasiones, habiéndome centrado en el paradigmático caso de los Cruzelaegui: «Hijos de la mar y comerciantes de Indias. Bienes artísticos en casa de los Cruzelaegui (Sevilla, m. XVII)», Cuadernos de los Amigos de los Museos de Osuna, 21, 2019, pp. 58-62.

11 AHPS, 12938, fol. 305vto; 4-V-1654.

12 «Vn niño Jesus con su peaña dorada y vn contadorçito pequeñuelo ençima del q esta el dho niño con vn pie de contador que esta el dho niño». AHPS, 1265, fol. 475vto; 1-VII-1649. En «Abril para morir: colecciones artísticas sevillanas en el año de la peste (1649)», op. cit., p. 264, v. 2. 
que lo conpre de man ${ }^{1}$ de morales escultor y una hechura de un santo xpto de bronçe que lo erede de doña fran antt ${ }^{\circ}$ de flores donçella difunta las quales dhas dos pieças // quiero y es mi voluntad que el dho mi hermano llama vna perss ${ }^{\mathbf{a}}$ que apreçie sus hechuras ...».13 Otros documentos relativos no tanto a los autores como a la demanda, sobre todo con manifestación de las emociones devocionales, nos aportan más noticias sobre este menudeo artístico.

Aun cuando el gusto por la escultura de bulto redondo se impone, por acomodarse más las sensibilidades locales, en su defecto podía ser sustituida por lienzos ${ }^{14}$. A modo de ejemplo, recordemos que doña Margarita de Echegoien, hija del platero del mismo apellido, llevó como parte de su dote un lote de pinturas, con un concepto similar al que podría haber tenido en la adquisición de obras escultóricas: un «Nacimiento», tasado en 80 reales, una Concepción, en 100 reales, un Cristo de la Expiración, también en 100 reales, y «un niño Jesús Cardenal» (a 57 reales). ${ }^{15}$

He podido constatar que son las Concepciones y los Crucifijos las piezas centrales del repertorio sacro en los hogares sevillanos de la segunda mitad del siglo. Y habitualmente atesorando varios ejemplares, como ocurre en el caso de Felipe de Quevedo y de Sebastiana de Mesa, que tuvieron por vía dotal «una hechura de Santo Christo de una tercia de largo con la cruz y peana dorada», una hechura de «la Espiracion con la peana y cruz dorada y negra» y «una echura de un santo Christo de marfil de una quarta de largo con la cruz de euano» ${ }^{16}$. Y asimismo un «niño Jhs de vulto de una quarta de alto» y una «limpia Consepcion» de una vara. ${ }^{17}$

Otro ejemplo, del capitán Juan de Trujillo Molina, fallecido en 1669, quien tenía a la hora de su muerte, tal como lo relaciona su viuda, «la hechura de vn ssto xpto de Bulto pequeño con su sitial de brocatel carmesí y amarillo», que lógicamente se localizaría en el oratorio, quizás junto con otras interesantes piezas, como «la hechura de un sto xptto pequeño de marfil con su peaña y guarneçido de platta sobre evano», u otras dos tallas de Nápoles, un Niño Jesús («un niño Jesús de bulto hechura de Nápoles con su caxa») y un san Juan («la hechura de $\mathrm{ss}^{\mathrm{n}}$ Joan hechura de Nápoles con su caxa»). Y un pequeño detalle que no se nos debe pasar por alto en relación con estas dos últimas obras: ambas estaban en sus respectivas cajas, quizás fanales. ${ }^{18}$

13 AHPS, 3694, fol. 944r [941-945]; 1657.

14 Jesús Urrea fijó diferencias en su texto sobre la escultura madrileña, en estos términos: «En Madrid la pintura primó sobre la escultura... El nivel ideológico y cultural madrileño era más elevado que el que se respiraba en provincias y por este motivo la pintura tuvo una mayor aceptación. La escultura por su carácter de inmediatez, de fácil comprensión, asequible al pueblo va a quedar relegada a desempeñar un papel de veneración, en el que los valores estéticos pocas veces interesan al espectador.» Urrea, J., «Introducción a la escultura barroca madrileña. Manuel Pereira», BSAA, 43, 1977, p. 253.

15 AHPS, 12982, fols. 1076-1078; 19-VI-1668.

16 AHPS, 13002, fol. 170r [170-172]; 20-IX-1675.

17 Idem, fol. 171vto.

18 AHPS, 3718, fols. 1053 r/v [1051-1057]; 20-X-1669. 


\section{DE GÉNERO Y MATERIA SE TRATA}

El capitán Trujillo no es el único a quien podríamos situar en este escenario artístico caracterizado por la diversidad, propia de una ciudad portuaria que «un mundo en cifra retrata», al decir de Lope. ${ }^{19} \mathrm{Y}$ así se agregaban a los productos locales tallas novohispanas, peruanas, napolitanas y hasta filipinas. No es raro, por tanto, encontrar en un mismo espacio un Niño napolitano junto a un crucifijo de marfil llegado desde el mar del Sur.

Luisa Elena Alcalá, a propósito de la provisión de escultura napolitana en territorios hispanos, pese a que los talleres peninsulares y virreinales tenían capacidad más que suficiente para atender la gran demanda, sugería que era cuestión de gusto ${ }^{20}$. Un gusto que se recreaba en una estética divergente de la concebida como propia, siendo más refinada y, quizás, elegante. ${ }^{21}$ Pero no se puede negar que la fama consolidada entre las élites también contribuyó a su éxito en el medio sevillano.

A fines del XVII crece la demanda en España de escultura napolitana, apreciada entonces por ser «más dulce y menos realista que la española» y también más acorde con ese aire de modernidad que corre desde la Península vecina, más intenso bajo el reinado de Carlos III. ${ }^{22}$ Y es posible que Cádiz se elevara al rango del principal emisor de este arte hacia Sevilla, superando en ello a la propia Corte. El cosmopolita enclave gaditano favoreció el asentamiento de artistas italianos, al tiempo que la bonanza económica estimuló la presencia de comerciantes de la misma procedencia. Aparte de la comunidad napolitana hay que destacar la genovesa. De este mismo origen eran los escultores Francisco Galeano, Antonio Molinari o Jacome Vacaro. También se ha distinguido la presencia de Juan y Francisco Martola, cuyo nacionalidad se duda. ${ }^{23} \mathrm{Y}$ de entre los napolitanos sobresalió Gaetano Patalano que hizo el relieve de la coronación de la Virgen para la catedral vieja. ${ }^{24}$ Y sin negar esta fuerza de irradiación del enclave costero, me pregunto si ello fue también así a mediados del XVII. Las fuentes constatan la presencia de escultura napolitana, por esas fechas, en Sevilla.

Fueron principalmente comerciantes, muchos vinculados a la Carrera de Indias, quienes poseyeron piezas con este origen. El afamado Bartolomé de San Martín Alberdi,

19 Lope de Vega, El Arenal de Sevilla, Barcelona, Sebastián de Comellas, 1618, acto 1, p. 223.

20 Alcalá, L. E. «...Fatiga, y cuidados, y gastos, y regalos...: Aspectos de la circulación de la escultura napolitana a ambos lados del Atlántico», Libros de la Corte, 5, 2017, pp. 163-184.

21 Luisa Elena utiliza el concepto de «negociación estilística» para explicar en cierto modo el éxito de la plástica napolitana en tierras hispanas. Idem.

22 López Jiménez, J. C., «Escultura barroca italiana en Levante y Sur de España», Boletín de la Real Academia de Córdoba de Ciencias, Bellas Letras y Nobles Artes de Córdoba, 85, 1963, p. 83.

23 En uno de los primeros estudios sobre la escultura italiana en el barroco andaluz se siembra esta duda, si napolitanos o genoveses. López Jiménez, J. C., «Escultura barroca italiana en Levante y Sur de España», Boletín de la Real Academia de Córdoba, op. cit., p. 79.

24 Di Lustro, A. Gli scultori Gaetano e Pietro Patalano, tra Napoli e Cadice. Nápoles, Arte tipográfica, 1993. Para mejor encuadrar esta producción foránea véase: Gila Medina, L. y Herrera García, F. J., coords. El triunfo del barroco en la escultura andaluza e hispanoamericana, Granada, EUG., 2018. 
fallecido en 1668, tuvo en su casa de la collación de san Nicolás, en el barrio mercantil por excelencia, una «hechura de un niño Jesús de Nápoles». ${ }^{25}$

Por su parte, Juan de Lizarralde tenía en su domilicio de santa María la Blanca hasta cuatro esculturas napolitanas (san Juan Bautista, la Pura y Limpia Concepción, dos Niños Jesús). Así consta en el inventario realizado por su viuda en 1664. Era oriundo de la villa de Plasencia, en Guipuzcoa, y había sido capitán con tratos en América y vínculos con la flota de Tierra Firme. Ello podría explicar que, además de las citadas piezas, tuviera dos Niños «de Sevilla», un Crucifijo de marfil. ${ }^{26}$

Abundando en ello, recordemos que Juan de Olarte, que había sido comprador de oro y plata, dejó a su muerte -en 1655- una muestra de este arte, además de otras de producción local y hechas en pasta. ${ }^{27}$ Suyas eran

«Una hechura de vn niño Jesus de napoles con su peaña dorada que costo mill Rs de pta. Una hechura de nuestra señora de pasta de tres quartas.

Dos bestidos de la ymagen, vno de tela blanca y otro de lama anteada con guarniçion de oro.

Una hechura de vn niño Jesus pequeño de pasta.» ${ }^{28}$

Curiosamente, un personaje con raíces genovesas, Diego Almonacid Spínola, también prefirió la pasta a la refinada escultura napolitana. De su propiedad era, por ejemplo, «una figura de pasta colorada con una peanita de platta». ${ }^{29} \mathrm{Y}$ con ser tan llamativa esta entrada, no constituye una rareza. En otros hogares se han podido registrar referencias a imágenes de Jesús Niño o de Cristo crucificado, habitualmente asociados con el oratorio. ${ }^{30}$ Son abundantes las citas a esta imaginería. Así, por ejemplo, conocemos que doña Ana Carrillo, viuda del platero Manuel García, distinguió entre sus bienes artísticos «dos hechuras de Jesuxpto cruçificado, la vna de papelon y la otra de pasta». ${ }^{31} \mathrm{O}$ la de Domingo Barrero, quien además de treinta y seis cuadros de «diferentes devociones» tenía «un santo xpto crucificado de pasta de tres quartas con su sitial». ${ }^{32}$ Asimismo, me parece

25 AHPS, 3716, fol. 234r; 26-VI-1668.

26 AHPS, 3707, fol. 428vto [428-429]; 21-III-1664.

27 Juan de Olarte, de origen vasco. De Otazu, A. y Díaz de Durana, J. R., El espíritu emprendedor de los vascos, Madrid, Sílex, 2008, p. 166. Por «Maestre de plata» lo menciona Enriqueta Vila en su estudio «Los maestres de plata: Un resorte de poder en el comercio de Indias», in Ortiz de la Tabla, J., PérezMallaína, P. E., Hernández Palomo, eds. Entre Puebla de los Ángeles y Sevilla. Homenaje al Dr. José Antonio Calderón Quijano, Sevilla, Universidad, 1997, pp. 128 y 131

28 AHPS, 17030, fol. 94vto. 28 de mayo de 1655.

29 AHPS, 17015, fol. 97vto. 15-IV-1651. Nos queda la duda sobre la identidad de este individuo. Quizás podría vincularse al empresario teatral sevillano.

30 En el inventario de bienes de Antonio Montero de Espinosa, que vivía en San Vicente, figura «un niño jesus de pasta». AHPS, 2653, fol. 612; 17-VIII-1653.

31 AHPS, 551, fol. 506r. 12-VII-1652.

32 AHP, 11850, fol. 418-419; 1-XI-1650. 
interesante el caso de Rodrigo Ortiz, que vivía a la vera del río, quien aparte de un gran nacimiento, con «dibersas hechuras de barro y madera como ciudades y palacios y otras casas», tenía «una ymaxen de la consepsion de pasta», situado en su retablo de la capilla familiar. $^{33}$

Estas y otras piezas nos llevan a considerar el lugar que ocupan en el medio artístico local los talleres de escultura en pasta, en el caso de considerar tal especificidad creativa. Lo cierto es que las fuentes permiten separar algunos nombres asociados a esta manifestación del arte escultórico. Singularizo el caso de Jerónimo López que ejerció con el título de «maestro de hacer imaginería de pasta». ${ }^{34}$ Después de años de dedicación a esta labor se examinó, en 1655, del arte de pintor «de lo que ttoca a el dorado de mate y encarnado en ttodo jenero de pasta y ffiguras de madera como no pasen ni esedan de media vara de $\operatorname{largo».}{ }^{35}$

Semejante cualificación le acreditó ante el Cabildo secular, para quien hizo «los jigantes y tarasca y mojarrillas» de la danza del Corpus, a mediados de siglo. ${ }^{36} \mathrm{Y}$ también pudo beneficiarse de la demanda conventual, puesto que las comunidades religiosas tuvieron especial predilección por esta materia, aunque la mayoría de las piezas les llegó por legado testamentario. Así, de la almoneda de los bienes del difunto Gerónimo de Alfaro obtuvo fray Marcos de Ariça, de la orden de San Juan de Dios, «la hechura de un sto xpto de pasta». ${ }^{37}$ A propósito de este dato, no está de más recordar que algunos de los más importantes ejemplos de la imaginería en pasta de caña de maíz, de procedencia novohispana, acabaron ingresando en el ámbito monacal. Baste el caso, tan divulgado, del Cristo del Capítulo, adquirido por los jerónimos de Bornos en 1553. Una efigie que ha sido objeto en los últimos años de diversos estudios dada su configuración y procedencia. ${ }^{38}$

33 «Yt vn altar que se conpone de un retablito dorado llano con una ymaxen de la consepsion de pasta con su bestido de tela encarnada y corona de plata sobredorada= con unos sarsillitos de perlas.» AHPS, 16414, fol. 705; 10-XI-1708.

34 Gestoso dio a conocer el oficio de López: «Gerónimo López que hace imágenes de Pasta en la Carpintería». Gestoso y Pérez, J. Ensayo de un diccionario de los artífices que florecieron en Sevilla. Desde el siglo XIII al XVIII inclusives, Sevilla, Oficina de la Andalucía Moderna, 1899, p. 224.

35 AHPS, 3690, fols. 942-943; 12-VI-1655. Lo examinaron Juan Chamorro, Manuel de Aguilar, Juan de Barreda y Juan de Garay.

36 Gerónimo López, maestro de hacer obras de pasta, vecino de la collación del Salvador, en la Carpintería, da carta de pago a Alonso de Ortega, mayordomo de propios y rentas de la ciudad, de 2700 reales «los mismos que por libramiento de su señoría el cabildo y regimiento de la ciudad se me mando pagar adelantados por los mismo en que se obligó en favor de la ciudad cabildo y regimiento y a la comisión de la fiesta del corpus xpti «de sacar la bispera y dia de dha fiesta del corpus deste año de mil y seisçientos y çinquenta y dos y su otaba la dansa de los Jigantes y tarasca y mojarrillas en conformidad y según yo lo e hecho otros años como se rrefiere en el dho libramiento». AHPS, 11854, fol. 979; 7-V-1652.

37 AHPS, 3715, fol. 7vto; 3-I-1668.

38 Hoy se encuentra en la iglesia parroquial de Santo Domingo de la misma localidad. El Instituto Andaluz de Patrimonio Histórico la sometió a una profunda restauración, tal como se resumen en la «Memoria Final». María Teresa Real Palma dirigió la intervención y coordinó dicho documento: Memoria Final de Intervención. Crucificado del Capítulo. Iglesia de Santo Domingo de Guzmán, Bornos, Cádiz. Septiembre de 2013. Edita IAPH, Consejería de Cultura. Otras imágenes de pasta de maíz se han estudiado asociadas 
Retornando a López, quiero recordar que fue padre de otro escultor, muy conocido en el medio gaditano, Ignacio López. ${ }^{39} \mathrm{Y}$ aunque no hay referencias formales para reconocer su magisterio, sí parece significativo el hecho de que se le ha vinculado, en lo formativo al menos, con Pedro Roldán..$^{40}$ En este encuadre laboral también hay que resaltar la estrecha relación que tuvo con dos importantes maestros de la madera de mediados de siglo, sus compadres Martín Moreno y Alonso Martínez. ${ }^{41}$

El lineamiento profesional de López no difiere mucho del de Evaristo López, que unos años antes había pasado por la misma prueba, siendo examinado «en el artte de enttallador de pastta y encarnador y dorador de la dha pasta que es de matte», pudiendo ejercer el oficio y tener tienda pública, siempre que no hiciera «obra de Romano ni de ffiguras por no esttar como no esta examinado para ello...». ${ }^{42} \mathrm{Y}$ quizás también con un enigmático «Pedro de la Md», tal como figura en las fuentes. ${ }^{43}$

No es nueva la noticia sobre la convergencia de las artes del dorado y la talla en pasta. Varias décadas antes, en febrero de 1579, el pintor Juan de Santa María contrató con la cofradía de la Soledad, en la iglesia de san Pedro de la villa de Cartaya, la hechura un Cristo resucitado «de bulto de pasta». El documento no deja lugar a dudas del compromiso profesional del pintor. ${ }^{44}$

a comunidades religiosas en la provincia de Sevilla, como los Carmelitas de Sanlúcar la Mayor, Santa Paula, Santa María de Jesús y el Socorro, en Sevilla, entre otras. Más en: Amador Marrero, P. F., Imaginería ligera nohovispana en el arte español de los siglos XVI-XVII. Tesis doctoral defendida en Universidad de las Palmas, 2012, en repositorio de la Universidad. Otra lectura desde México: Estrada Jasso, A., Imágenes en Caña de Maíz, San Luis de Potosí, Universidad Autónoma, 1996.

39 Moreno Arana, J. M., «La diusión del barroquismo sevillano en El Puerto y su entorno: Ignacio López y Alonso de Morales y su retablo de Ánimas de La Prioral (s. XVII-XVIII)», Revista de Historia de El Puerto, 37, 2006, pp. 47-80.

40 Moreno Arana quien establece el vínculo en razón de la familiaridad estética entre el arte del maestro y la del supuesto discípulo. «Ignacio López y la escultura portuense», op. cit., p. 47.

41 Testamento. AHPS, 12971, fol. 606. 1664. De ello se hizo eco Teodoro Falcón en: «El arquitecto de retablos y escultor Martín Moreno y los primeros retablos con columnas salomónicas en Sevilla», Boletín de Arte, 34, 2013, p. 72.

42 AHPS, 1805, fol. 124; 9-I-1651. En 10 de enero Sebastián de Llanos, alcalde del mismo arte, dijo que era del mismo parecer. El documento es bastante explícito: «En la muy Noble y muy leal zivda de seui ${ }^{\mathrm{a}}$ en nueue dias del mes de hen ${ }^{\mathrm{o}}$ de mill y seisçienttos cinquentta y un años ante mi el preste $\mathrm{s}^{\mathrm{no}} \mathrm{pu}^{\mathrm{co}} \mathrm{y}$ $\mathrm{tt}^{\mathrm{ts}}$ pareçio Juan fax ${ }^{\mathrm{do}}$ alcalde del artte de pinttor ve $\mathrm{z}^{\text {no }}$ destta dha civdad en la collaçion de Sant Pedro $\mathrm{y}$ dixo y declaro que el ha visto y examinado a a [sic] Evaristto alvares $\mathrm{v}^{\text {no }}$ de estta dha zivdad en el artte de enttallador de pastta y encarnador y dorador dela dha pasta que es de matte y le a vistto obrar en el dho artte de enttallador encarnador y dorador de la dha pastta y le ha hecho ttodas las pregunttas y repregunttas a ello ttocanttes y perteteneçienttes y le ha allado abill y sufiçientte en ttodo ello= $\mathrm{y}$ ansi como persona examinada y abilittada en el dho arte pueda $t^{\text {ner }}$ en estta dha zivdad y en ottras qualesquier parttes y lugares su tienda publica y $\mathrm{tt}^{\text {ner }}$ y Rezeuir aprendices y offiçiales sin yncurrir por ello en pena $\mathrm{alg}^{\text {na }}$ por quanto es abil y sufiçientte para exercer el dho arte y con que ni ha de poder el dho Evaristo alvares haçer obra de Romano ni de ffiguras por no esttar como no esta examinado para ello...»

43 Espinosa de los Monteros Sánchez, F., «Nuevas aportaciones a las vidas y obras de Ignacio Francisco López y Alonso de Morales», Revista de Historia de El Puerto, 42, 2009, p. 78.

44 Gestoso, op. cit., vol. II, 1900, p. 103. 
A la popularización del arte napolitano y al éxito de la escultura en pasta pudo contribuir de una manera decisiva el Belén o Nacimiento. ${ }^{45}$

Este pequeño y efímero universo, creado y recreado, en un ciclo mítico que entrañaba el retorno permanente, fue más que una tradición familiar: constituyó un sistema expresivo que se nutrió de múltiples experiencias artísticas en cuya modulación intervinieron hasta las propias familias poseedoras. La fragilidad de estas construcciones ha hecho que en su mayor parte hayan desaparecido y que hoy apenas tengamos fugaces imágenes, obtenidas en las siempre bien nutridas colecciones conventuales.

El belén sevillano fue una expresión de la religiosidad, pero también una manifestación de los usos artísticos de la sociedad. En su concreción se produjo la concurrencia de artistas de diversa condición, impulsados por ideas también heterogéneas. Los escultores compartieron tarea con otros artífices, e incluso hubieron de mostrar su versatilidad técnica, trabajando la madera, la pasta e incluso el barro. ${ }^{46}$

Dada la heterogeneidad material y la complejidad compositiva del género, fueron pocos los artífices que mostraron a plenitud su comprensión del mismo. Quizás sea una impresión errónea derivada de la falta de indicios claros. Ausencia de pruebas que incluso ha afectado al gran maestro del barroco sevillano, Pedro Roldán, de quien se ha podido saber que estuvo involucrado en la creación de al menos dos belenes. ${ }^{47}$

Diversas circunstancias silencian los nombres de los artífices belenistas. Ante todo el rango artístico de esta producción, tanto como el carácter de la demanda. Era diverso en lo cualitativo y en la significación de cada una de las partes. También estaba condicionada por su escasa longevidad, al ser conjuntos que tenían difícil conservación dada la multiplicidad de componentes. El Portal cobijaba a la Sagrada Familia («Nacimiento») y se situaba al frente de la composición, sirviéndose del Cortejo Real como conector y quedando el resto de las figuras colocadas por añadidura. Las mermas que se producían habitualmente eran subsanadas con nuevas piezas, que podían ser obra de otros artífices e incluso elaboradas en otros materiales. ${ }^{48}$

Algunos pasajes extraídos de entre los documentos notariales nos ponen en antecedentes sobre la presencia de los Nacimientos en los hogares sevillanos. He ahí que el trianero Rodrigo Ortiz poseía, en 1708, «vn nacimiento grande que se compone de

45 Uso el término popularizado entre los estudiosos, pero el que se aplicó en su momento fue el de «Nacimiento».

46 García Olloqui, M. V., «La iconografía de «La Natividad» en la obra de La Roldana. El problema de los belenes atribuidos. Diferencias, estudio estilítico y opiniones cualificadas», Fuentes, 1, 1998, s. p. José Roda, con buen criterio, reduce a cinco los Belenes seguros de La Roldana. Roda Peña, J., «La escultura sevillana del pleno barroco y sus protagonistas durante la segunda mitad del siglo XVII», in Gila Medina, L. y Herrera García, F. J., coords. El triunfo del barroco en la escultura andaluza e hispanoamericana, Granada, Universidad, 2018, p. 249.

47 En prensa tengo un estudio sobre este capítulo en la producción de Roldán.

48 Parece contradecir lo dicho el hecho de que los conjunto conservados en los conventos sevillanos pueden ser obra del mismo taller. 
dibersas hechuras de barro y madera, como ciudades y palacios y otras casas» ${ }^{49}$. Por su parte, la marquesa de Moscoso, doña Luisa de Neve, tenía otro, que donó, en 1687, a la Escuela de Cristo. ${ }^{50}$

Pese al desgaste formal y a la dificultad para tipificarlo como arte, hoy se valora su aporte al servir de campo de experimentación creativa, estimulando la inventiva de algunos artistas. Y al fin, con Valiñas, hay que significar su importancia:

«...la historia del arte ha de aproximarse al belén considerando que, aunque muchas de sus muestras contemporáneas se presenten bastante hueras en su enjundia conceptual y harto romas en su mérito plástico, en sus expresiones pretéritas, el belén sí tuvo una entidad artística a la altura de las manifestaciones más perfectas del genio de su tiempo, siendo portador, no sólo de lo mejor del imaginario formal de cada ambiente, sino también de las pulsiones del sentido devoto, social y estético de la época y el lugar en que hubiese brotado». ${ }^{51}$

\section{DEL HOGAR A LA IGLESIA}

Es un hecho que gran parte de las imágenes de culto privado, una vez desmanteladas las casas al paso del tiempo y perdido el rastro de sus propietarios, sólo podemos localizarlas en las fuentes y, en el mejor de los casos, en su última morada, a la que fueron derivadas generalmente por vía testamentaria. Las élites sevillanas, poseedoras de estos objetos de valor, tuvieron por costumbre trasladarlos a recintos sagrados. Garantizar el bienestar de la familia era importante, tanto como cuidar de estas valiosas pertenencias.

Es el caso de doña Mariana Cuello, que vivía con su esposo, el capitán Lorenzo Gómez, en santa María la Blanca. Hizo testamento en noviembre de 1659, poniendo en manos de la Iglesia un Niño Jesús: «...si justare [sic] de ello el dho capitan Lorenzo gamez mi marido se le de a la dha Yglesia vn niño jesus de bulto que tengo en mi casa que es el que llamo mi mayorazgo por tener otros de bulto.» ${ }^{52}$

A este respecto, me parece muy representativo el documento que refiere cómo doña María Manuela, hija del platero de oro Cristóbal Rodríguez, se llevó a la celda que poseía en el convento del Espíritu Santo una imagen de bulto del Rosario. ${ }^{53}$

49 AHPS, lib. 16414, fol. 705; 10-XI-1708.

50 Sevilla, 15/11/1687. Certificación del secretario de la escuela de Cristo Nuestro Señor de Sevilla de la donación que hizo Luisa de Neve, marquesa del Moscoso de un nacimiento para el oratorio de dicha escuela. Vilela Gallego, P., Catálogo de los documentos del Archivo de los Condes de Gómara y familia Arias de Saavedra, Sevilla, Consejería de Cultura, 2009, p. 38.

51 «El belén ante la historia del arte. Apuntes para el estudio de sus elementos contenidos escenográficos». Cuadernos de Arte de Granada, 40, 2009, pp. 416-7.

52 AHPS, 12957, fols. 855-856; 25-XI. Cita en fol. 856r.

53 Doña Ana Carrero le legó la citada pieza a través de su testamento. AHPS, 12955, fol. 851vto; 5-IV1659. 
En el mismo sentido se manifestó doña Mariana de Castro, quien dio al convento de Santa Clara de Utrera -a fines de 1654- 200 reales, para costear el hábito de una monja por la que sentía afecto, a la que legó además «quatro cuadros, uno de sr. san fran ${ }^{\text {co }}$ y otro de la visitaçion de nuestra $\mathrm{s}^{\mathrm{ra}} \mathrm{y}$ otro $\mathrm{d}$ ela concepçion purisima de nuestra $\mathrm{s}^{\mathrm{a}}$ pequeño y tiene la moldura de ébano y el otro de un niño Jesús y la pido me encomiende a dios nuestro señor». ${ }^{54}$

La entrega de un bien atesorado en el hogar tiene tanto que ver con el deseo de preservación, como con el de sostenimiento de la honra familiar. Generalmente son imágenes de las que se cuidan, hasta en los mínimos detalles, como el atuendo. Es lo que ocurre con la Virgen de los Reyes, de la devoción de doña Leonor de Ortega, que pide «con amor» al convento franciscanos descalzos de san Pedro de Alcántara, la tengan en su iglesia nueva, con su vestuario. ${ }^{55}$

Igualmente es muy significativa la actitud de doña Catalina de Medina Blázquez, con respecto a un san Sebastián de marfil, que le pertenecía. Era tal el afecto que sentía por él que llegó a imponer su conservación en el hogar aún después de muerta. En el testamento, otorgado por poder por su viudo, Sebastián Blázquez, vino a exigir:

«Que vna hechura de San seuastian de Marfil que la susodha tenia de vna terçia poco mas de alto la qual no se pudiese vender ni enajenar y fue su voluntad que mientras yo el dho Don sebastián blázquez y el dho Don Aluerto marçelo Blázquez mi hijo lexitimo y de la dha Doña Catalina de meidna Blázquez durante los dias de mi vida y de la del dho mi hijo y durante los dias de las uidas de los demas mis hijos lexmos del dicho mi hijo si yo o el susodho los tubierieremos estubiese la dha hechura como a de estar en mi poder y del dho mi hijo y de los demas mis hijos y suios y descendientes dellos y a fatltta de los dhos hijos y descendencia fue la voluntad de la dha Doña Catalina de medina Blázquez de mandar como nosotros en su ne mandamos la dha hechura de señor ssn Sebastián // a la capilla de nra ssra del Rosario del Colegio de rreija angelorum desta ciudad...» ${ }^{56}$

Por no alargar más esta relación, concluyo con don Jacinto Mexía de Vargas Machuca, cura del Sagrario, oriundo de Sanlúcar de Barrameda, en cuyo convento de santo Domingo, concretamente en la capilla de san Gregorio, se encontraba enterrado su padre,

54 AHPS, 12940, fol. 483r [482-485]; 30-XI-1654.

55 «Yten mando y es mi boluntad que vna ymajen de bulto de bestir que tengo en mi casa que es de mi deboçion y nonbre de nuestra sra de los reyes mando se le de a el convento de San Pedro de alcantara de esta çiud que es de descalsos de mi Pe st franco q esta en la collaçion de st andres y les pido por amor de nro sr me la coloquen y tengan en la ygleçia nueba que de presente estan labrando» junto con el arco de todos sus bestidos y dos tocas con sus rostrillos de perlas, con las joyas, que son un brazalete de piezas de oro y dobletes para el pecho y otro de perlas y cuentas de vidrio dorada de e vueltas // de perlas para cada muñeca y una rosa para el pecho de oro y dobletes y una lampara de plata que esta en mi casa y dos candeleros d eplata «y mas le mando dos ymajenes de dos anjeles y dos figuras de marmol blancas vna de san agustin y otra de sta monica» manda al convento. AHPS, 4446, fol. 712vto [708-716]; 13-VIII-1655. 
el capitán Juan Mexía ${ }^{57}$. Remitió a su hermana Ana Mexía de Vargas Machuca, mujer del sargento mayor don Lorenzo Gómez de Medina, «dos hechuras, una de vn niño Jhs dormido sobre una muerte con vn trono de Angeles y dos Angeles sueltos que acompañan los lados vno con la lanza y otros con la esponja y vna hechura de la Concep ${ }^{\text {on }}$ con su peana y corona de plata dorada y con relieues y piedras y su diadema de rayos y estrellas». Y a su comadre Josefa María del Pino y Alzola, viuda del jurado Fernando de Medina, «vna hechura de vn Sto Christo de talla con su sitial y mas dos hechuras de talla, la vna de vn niño y la otra de vn san Juan con sus peanas». ${ }^{58}$

\section{PRODUCCIÓN Y VENTA. DEL OBRADOR A LA TIENDA Y LA FERIA}

Me ha interesado constatar que junto con los escultores y tallistas son los doradores y estofadores quienes se involucraron en la concreción de esta imaginería menuda de consumo doméstico. Imaginería a la que podríamos considerar un género escultórico, a pesar de no tener un reconocimiento implícito en el régimen estatutario de estos oficios. A tenor de los exámenes de escultura y talla, sabemos que era tan importante el trabajo de imaginería como el de arquitectura y ensamblaje. Desde 1573 se diferenciaba, entre talleres, la realización de un desnudo y de una imagen de candelero, del diseño, ensamblaje y talla a lo romano de un tabernáculo. ${ }^{59} \mathrm{Al}$ fin la labor arquitectónica se eleva al mayor rango a nivel instructivo, con implicación de las artes del dorado y estofado. Incluso las Ordenanzas de la ciudad son muy explícitas al respecto, al consignar como parte en la formación del entallador, «ser buen debuxador, y saber bien elegir, y labrar bien por sus manos retablos de grande arte, pilares revestidos, y esmortidos con sus tabernáculos, y repisas para imágenes, y tumbas, y chambranas trastocadas, con sus guardapolvos, con buelta redonda, y fazer tabernáculos de grande arte, y fazer coros de sillas ricos...» ${ }^{60} \mathrm{Y}$ sin embargo, será la imaginería donde los doradores verán limitadas sus competencias, al quedarles vedado el tratamieto de sus carnaciones. ${ }^{61}$

Al menos en las cartas de examen se da por formalizada lo que, en otro tiempo o circunstancias, podría considerarse una intromisión profesional. En la prueba de López, de junio de 1655 , a la que ya me he referido, se constata que era oficial examinado del

57 Era cura del Sagrario, pero sabemos que una década antes lo era de la parroquial de Sanlúcar de Barrameda. Concretamente en 1645 lo era, justo cuando escribe la Oración Panegírica y Evangélico Testimonio de la Concepción Pvra y sin mancha de original pecado, de Maria Madre de Dios. Impreso en la citada localidad, por Diego Péres Estupiñán, en 1646. Una copia del impreso en: Biblioteca Pública del Estado - Biblioteca Provincial de Cádiz — Signatura: BBH6 C1-6 - No de registro: 1003995.

58 AHPS, 13011, fol. 173r [168-176]; 2-IX-1678.

59 Bruquetas Galán, R., «Los gremios, las ordenanzas, los obradores», In Gabaldo García, A. y Ineba Tamarit, P., dirs., La pintura europea sobre tabla, siglos XV, XVI y XVII, Madrid, Ministerio de Cultura, 2010 , p. 5.

60 Bruquetas, op. cit. 6; Ordenanzas de 1526.

61 Literamente se dice: «a los que solamente son doradores no les permite que encarnen los rostros de las figuras de bulto sin estar examinados dello». Idem, 10. 
arte de pintor, «de lo que ttoca a el dorado de mate y encarnado en ttodo jenero de pasta y ffiguras de madera como no pasen ni esedan de media vara de largo». ${ }^{62}$ En este ilustrativo documento cabe resaltar el hecho de que se limite el tamaño de las figuras, a media vara, lo que estaría normalizando -como ya se ha resaltado arriba- un patrón creativo y de consumo privado. ${ }^{63}$ Además resulta interesante que en él se haga mención a «todo género de pasta». Para mayor abundamiento, el hecho de que el mismo artífice pudo ser quien por las mismas fechas está haciendo «imágenes de Pasta en la Carpintería. ${ }^{64}$

Las fuentes vuelven una y otra vez a reconocer la compenetración entre imagineros y pintores de imaginería, al menos desde el último tercio del XVI. Así, en 1574 el «pintor de ymagineria e ynpresos de ellas», se comprometió a enseñarle su arte a Cristóbal Gómez Saravia, estante en Sevilla, pero vecino de Lima. Precisando que habría de instruirle en lo tocante al «vaciado de medio relieve e bulto entero e de pasta yeso y tierra e pintado al temple e barniçarlo». ${ }^{65}$ Y más: unas décadas más tarde, en 1610, otro pintor, Bernabé de Baeza, se obligaba a hacer «seiscientas hechuras de cristos de barro cocido hechos en toda perfeccion», de las que un tercio sería de cuarta y media, otro de una cuarta y el resto de poco menos. ${ }^{66}$ Por Pacheco sabemos que Pablo de Céspedes, aunque pintor, modeló en cera de colores, si bien ello se explica como soporte de las ideas que luego se materializarían en la pintura. ${ }^{67}$

La documentación consultada me permite identificar un cambio en el funcionamiento de los oficios de la madera, al menos por lo que respecta a la demanda. De hecho, la afluencia de obras americanas que fueron del gusto de la clientela obligó a introducir sutiles cambios a nivel de talleres. Los maestros escultores, si bien mantuvieron cierto nivel de ventas, ya no gozaban de la demanda de décadas anteriores. Incluso en tierras americanas se aminoró el volumen de compras, tanto en las sedes virreinales como en la importante feria de Portobelo ${ }^{68}$.

62 AHPS, 3690, fol. 942r [942-943]; 12-VI-1655.

63 La estandarización de esta medida es un hecho. La reducida dimensión contribuye a «acortar la distancia» y a «potenciar la comunicación» entre el concepto materializado en la escultura y su poseedor o poseedora. Y aunque en algún caso se valora el papel de religiosos y religiosas en la creación de estos objetos de culto, generalmente dentro de un ámbito monacal, tuvo que ser mayor la producción de talleres para demanda no cenobítica. A imagen y semejanza, op. cit., pp. 18 y 19.

64 Documentado por Gestoso, op. cit., 1899, 224; y considerado su vínculo Ignacio López por José M. Moreno Arana. «Ignacio López y la escultura portuense...» op. cit., p. 47.

65 López Martínez, C., Desde Jerónimo Hernández hasta Martínez Montañes. Notas para la Historia del Arte, Sevilla, Tipografía Rodríguez, 1932, pp. 195-196.

66 De Bago y Quintanilla, M., Hernández y Díaz, J. y Sancho Corbacho, H., Documentos para la Historia del Arte en Andalucía, Sevilla, 1928, p. 240, t. 2.

67 Incluso algunas piezas se pudieron registrar como parte de sus bienes en el inventario post mortem. Pacheco, F., El Arte de la Pintura, ed. B. Bassegoda, Madrid, Cátedra, 1990, p. 440, n. 11. Martínez Lara, P. M., «Sedimento material de una vida humanista. El inventario de bienes de Pablo de Céspedes», Boletín de Arte, 32-33, 2011-2012, p. 443.

68 Se encuentra en prensa un ensayo en el que abordo parcialmente esta cuestión: «Transatlantic markets and the consumption of Sevillian art in the Viceroyalty of Peru. The Portobelo fairs in Tierra Firme (18th Century)». 
Los indicios documentales permiten sospechar en el aumento de la demanda interna de objetos tratados al gusto americano, con aplicaciones de metales nobles e incluso láminas embutidas. Los papeles notariales aluden a la significativa actividad de los ebanistas, siendo no pocos los escultores que fueron deslizándose hacia el ámbito de la ebanistería, Juan Medina, que firmaba como «escultor y ebanista». ${ }^{69}$

Al fin, será la creciente demanda americana la que animará el medio artístico sevillano, que hubo de atender las solicitudes llegadas desde los nuevos centros de culto. Nueva España y el Perú fueron atendidas en sus necesidades devocionales por imagineros locales, quienes actuarían, como decían las primeras ordenanzas novohispanas de 1569, como «adornadores del Credo divino». ${ }^{70}$

Aun cuando el uso y sentido de la pintura no es el mismo que el de la escultura, cabe considerar que pudo comercializarse a la par, también en stock, pero en menor cantidad. E igualmente se benefició de la intermediación de los agentes comerciales, tomando como base de operaciones la feria de Portobelo en Tierra Firme, puerta del Virreinato del Perú ${ }^{71}$. Y tambien se ha estudiado el sustancial cambio experimentado por el mercado artístico sevillano con el crecimiento exponencial de la demanda americana. Y el consiguiente cambio que se produjo en el funcionamiento de muchos talleres, tanto en sus estructuras como en los sistemas de trabajo, sustituyendo el concepto tradicional por otro cuasi industrial $^{72}$. Podría conferirse a la producción escultórica lo que Ceán Bermúdez decía de la pintura: «Antiguamente era mucho mayor el tráfico y despacho de estas pinturas que ahora, porque se embarcaban infinitas para América, lo que era otro nuevo estímulo para los progresos del arte, pues entonces no eran tan malas como las que en el dia se pintan, y muchos profesores de mérito, quando no tenian que hacer, acudían a los cargadores a Indias, que jamas dejaban de ocuparlos, pagándoles en proporción de su habilidad». ${ }^{73}$

Sin negar la existencia de conflictos con el monopolio de la Corona, principalmente ocasionados por los «peruleros», que quisieron sustraerse a estas imposiciones reales, el tráfico artístico fue fluido e intenso. ${ }^{74}$ Portobelo se situó al frente del negocio del menudeo de mercancías artísticas, al ofrecer las condiciones propicias para la venta en tienda, en

69 AHPS, 11857, fol. 286; 27-I-1653.

70 Maquívar, M. del C., «Los 'adornadores del Credo Divino': Imagineros barrocos novohispanos», III CIBI, Universidad Pablo de Olavide, Sevilla, p. 470.

71 Entre las muchas publicaciones que desde distintas perspectivas tratan el tema, me parece destacable por lo que significa su contenido: Palomero Páramo, J. M., «Notas sobre el taller de Zurbarán. Un envío de lienzos a Portobelo y Lima», in García, S., ed., Extremadura en la evangelización del Nuevo Mundo, Madrid, Sociedad Estatal Quinto Centenario, 1990, pp. 313-330.

72 José María Sánchez lo estudió: «Los obradores artísticos sevillanos del siglo XVI. Adaptaciones y cambios para satisfacer los encargos del mercado americano». Anales del Instituto de Investigaciones Estéticas, XXXV/103, 2013, pp. 177-196.

73 Carta de D. Juan Agustín Ceán Bermúdez a un amigo suyo sobre el estilo y gusto en la pintura de la Escuela sevillana y sobre el grado de perfección a que la elevó Bartolomé Estevan Murillo cuya vida se inserta, y se describen sus obras en Sevilla, Cádiz, Academia de Bellas Artes, 1806, pp. 36-37.

74 De ello me traté en: Sevilla y América en el Barroco, op. cit. pp. 130-133. Más en: Vila Vilar, E., «Las ferias de Portobelo: Apriencia y realidad del comercio con Indias». Anuario de Estudios Americanos, 
tanto que Lima ejerció como centro distribuidor de la producción de mayor envergadura, generalmente con encargo previo. Y artistas como Martínez Montañés tomaron el enclave costero como base de distribución de sus creaciones, las que generó masivamente con el respaldo de su gran taller. ${ }^{75}$ Empezó a trabajar para el mercado americano recién llegado a Sevilla, en 1590, cuando el dominico Cristóbal Núñez le encargó ocho esculturas de la Virgen del Rosario. ${ }^{76}$ Todavía más representativo es el envío de «veinte docenas de imágenes de estaño, costaron ocho reales, con destino a Nueva España». ${ }^{77}$ Años antes el pintor Bernabé de Baeza comprometió la entrega de «seiscientas hechuras de cristos de barro cocido hechos en toda perfeccion. ${ }^{78} \mathrm{Y}$ más tarde sigue vivo el trasiego, bien que con otros artistas. Así ocurrió con Alfonso Martín, quien puso en manos de don Pedro de Saldías, «las hechuras de vn niño e dos sanjuanes», para venderlas en Lima, como finalmente hizo. ${ }^{79}$

Las bodegas de los navíos que componían las flotas de Indias llevaban esculturas menudas de devoción ${ }^{80}$. Bien en la dirección arriba señalada, bien en la contraria. En el Arenal sevillano se descargaron numerosos cajones con piezas americanas. Abundan las noticias relativas a las remesas de plata y otros bienes suntuarios y artísticos, llegados de las Indias y repartidos por la Península a través de las cuadrillas de arrieros, principalmente yangüeses. Éstos ejercieron su tarea en forma de monopolio, distribuyendo las mercancías desde el puerto sevillano hasta la Cornisa Cantábrica, con reparto también en la Meseta. En referencia a ello podemos recordar el lote entregado por el capitán Juan Cruz de Gainza a los yangüeses Callejas y Pérez Caro, compuesto de 17 cajones, entre los que se encontraban los que contenían «tres echuras de Santo Cristo, los dos grandes y la otra pequeña, y un niño Jesús». Todo ello para llevarlo a Mondragón y entregarlo al capitán Juan Baptista de Barrutia. ${ }^{81}$

XXXIX, 1982, pp. 275-340; García Fuentes, L., Los peruleros y el comercio de Sevilla con las Indias, 1580-1630. Sevilla, Universidad, 1997.

75 Wuffarden, L. E. y Guibovich, P., «El clérigo Juan López de Vozmediano, comitente de Martínez Montañés en Lima», BIRA, 17, 1990, p. 420.

76 Hernández Díaz, José, Juan Martínez Montañes (1568-1649), Sevilla, Guadalquivir, 1987, pp. 96 y 99.

77 Ramírez Montes, G., Catálogo de documentos de arte en el Archivo General de Indias, México, UNAM, 1983, p. 27. También Porres Benavide, J., «Escultores y esculturas en el Virreinato de Perú a comienzos del Barroco», Revista del Instituto Riva-Agüero, 3/2, 2018, p. 176.

78 Bago, Hernández y Heliodoro, DHAA, op. cit., 2, pp. 240. Más en: Peña Martín, Á., «La circulación de modelos escultóricos en el territorio de la Monarquía Hispánica: el Niño Jesús dormido sobre la cruz y calavera del taller de Martínez Montañés», Copia e invención. Modelos, réplicas, series y citas en la escultura europea, Valladolid, Museo Nacional de Escultura, 2013, pp. 297-311; también: Porres Benavides, J. «El comercio de imágenes devocionales con América y la producción seriada de los talleres escultóricos sevillanos». Ucoarte, 2, 2013, pp. 9-16.

79 Cobró por ello 150 pesos. AHPS, 3699, fol. 23; 25-IX-1659.

80 Es interesante la asociación que hace Beatriz Prado-Campos entre la imaginería ligera y su lugar en el proceso colonizador: Prado-Campos, B., «Imaginería ligera. Un barroco al servicio de la colonización», In Fernández Paradas, A. R., aut., Escultura barroca española: nueva lecturas desde los siglos de oro a la sociedad del conocimiento, Antequera, Exlibric, 2016, vol. 1, pp. 151-170. 
En este punto caben otros «retornos», obras de escultura salidas de talleres peruanos, en forma de imágenes de devoción, mayoritariamente Vírgenes de Copacabana. Doce de ellas llevó consigo a Sevilla el capitán Gabriel Dávalos, que recién llegado de los reinos de Tierra Firme, entregó a doña Ana Bernal «doze ymagenes de popas cabanas [sic]», que fueron las mismas que había recibido en San Felipe de Portobelo de Juan de Garay, quien a la sazón vivía el El Callao. ${ }^{82}$

El capitán Pedro de Peralta llegó del Perú en los galeones del general Príncipe Montesarcho, a principios de 1668. Trajo consigo «un envoltorio aforrado», donde había, entre otros objetos «seis hechuras de ymaxines de nra ss ${ }^{\text {ra }}$ de Copa cauana, las quatro de a dos haçes y las dos pequeñitas». ${ }^{83} \mathrm{El}$ lote lo había entregado en Cuzco Santiago Sumalave, para entregarlo en Sevilla a Juan de Bringas, primo del emisario. Es posible que el destino último fuera el convento de Santa Clara de Balmaseda, donde profesaba María de Sumalave, hermana de responsable del envío. ${ }^{84}$

Y si los registros de vuelta de la Casa de Contratación no ofrecen datos sobre el consumo privado de estas imágenes, sí lo hacen los notariales, que en numerosas ocasiones relacionan imágenes de la Copacabana. Aunque es posible que fueran mayoritariamente de pequeño formato o dentro de altares portátiles. Así, en septiembre de 1665 estaba llegando a manos del capitán Juan de Bedía, en Balmaseda: «una ymajen de nuestra $\mathrm{s}^{\mathrm{a}}$ de copacabana de dos puertas ${ }^{85}$.

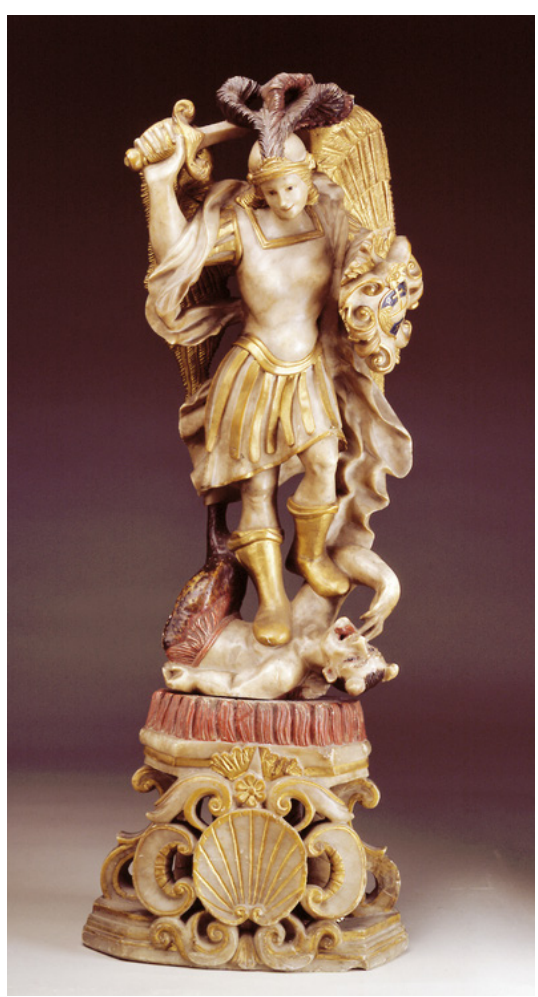

San Miguel Arcángel. Huamanga (Perú). Siglo XVII. Museo de América.

\footnotetext{
82 AHPS, lib. 13004, fol. 1348; 2-X-1679.

83 AHPS, 3715, fol. 194; 28-I-1668.

84 AHPS, 3715, fo. 528; 21-III-1668.

85 Aparicio de Ornes Berastegui la dio a Gaspar Berruezo para que la hiciera llegar a destino. AHPS, 3710, fol. 80; 4-IX-1665. Se ha fechado la recepción e inicio del culto de esta devoción en España en 1652, coincidiendo con el retorno de Perú del agustino fray Miguel de Aguirre, acompañando al virrey, marqués de Mancera. Luján López, F. B., «Nuestra Señora de Copacabana, una devoción andina patrona de Rubielos Altos (Cuenca). Su origen y difusión», Revista Murciana de Antropología, 8, 2002, p. 205. No obstante, años antes circula un impreso dedicado al Santuario: Historia del célebre santuario de Nuestra Señora de Copacabana, y sus milagros, e invención de la Cruz de Carabuco. En la imprenta de Jerónimo de Contreras, Lima, 1621.
} 
Juan Bernabé Palomino y Fernández de la Vega. Retablo de la Virgen de Copacabana de Madrid. Museo del Prado, s. XVIII. D003544.

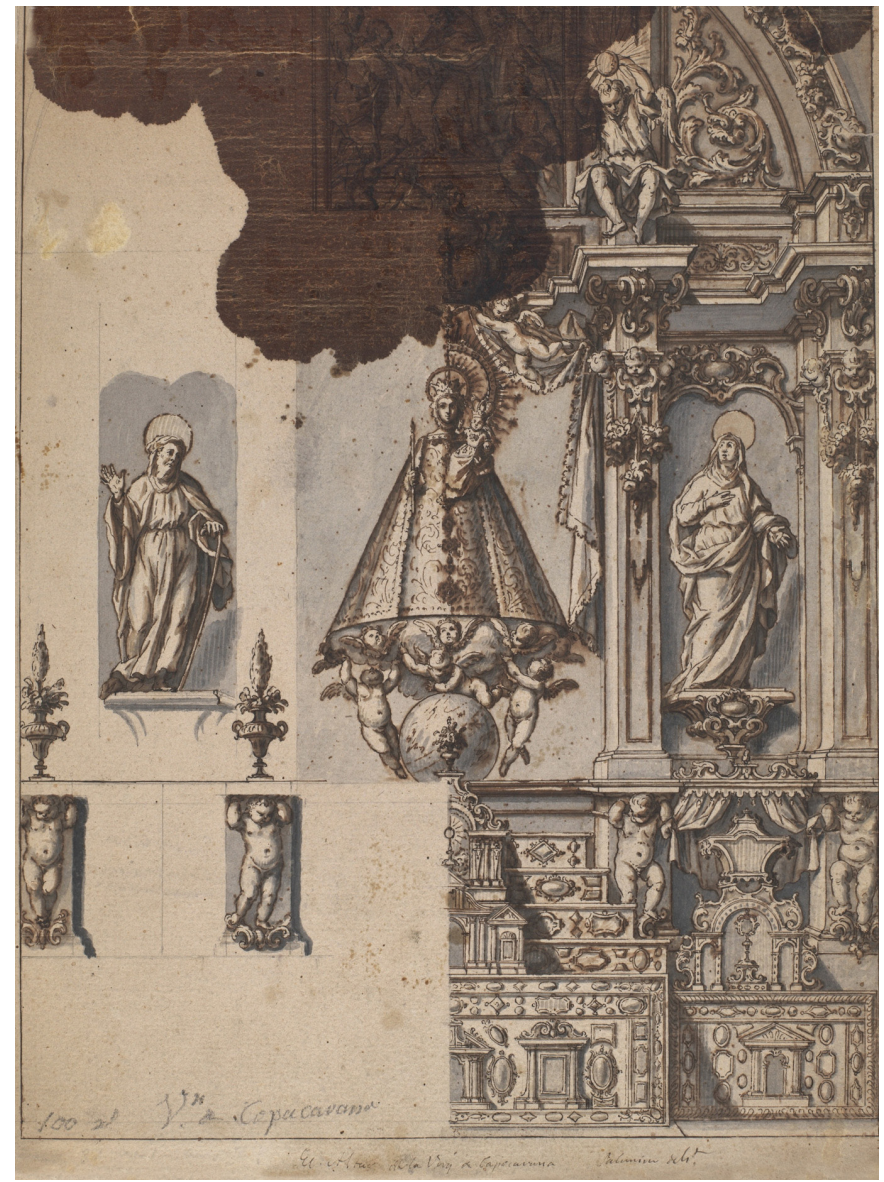

Y además de estas imágenes de procedencia peruana, también viajaron en las flotas en el retorno de las Indias, las de piedra de Huamanga y las de caña de maíz. Y de nuevo son las fuentes las que nos avisan de la existencia de muchas de estas obras americanas en los hogares sevillanos. Cristóbal de Cea, que pudo ser tendero, poseyó «una echura de tabla de un santo xpto echo en yndias de cañaexa [sic] con su sitial de tafetan morado y galon y flocadura morada y oro». ${ }^{86}$

Andrés Chamorro, fallecido con el contagio del 49, tenía entre sus bienes tres crucifijos. De ellos es sumamente interesante la referencia al segundo: «Yten otras dos ymajenes de xpto nuestro señor cruçificado de caña echa en la china que los trujo don melchor de melo para el dho andres chamorro». ${ }^{87}$

86 Noticia aportada por su viuda, doña Josefa Ruiz de Orellana, a través del inventario de los bienes del difunto. AHPS, 558, fol. 359vto; 20-IX-1654.

87 AHPS, 11853, fol. 212vto [210-213]; 5-VIII-1651. Quiles, F., «Lo mejor de cada casa», op. cit., pp. 208-209. 
No fue raro encontrar en la cargazón de las naos esculturas menudas de Huamanga («guamanga» en las fuentes). Hoy cuesta identificarlas, aunque con toda seguridad llegaron al puerto sevillano. A su villa natal, Valderas (León), el contador Gaspar de Ochoa, que a la sazón vivía en Lima, envió numerosas obras. A los carmelitas envió, entre otras piezas, «vn niño chiquito de piedra de guamarga y otro papel intitulado a el reverendo padre prior del convento del carmen de valderas». Igualmente otra al gobernador de la villa: «un papel intitulado par el sr gobernardor de la villa de Valderas y en él la hechura de un niño Jesús de piedra de guamanga». Y para el Buen Suceso «una cajita de palo calado y en ella un relicario de cristal con las

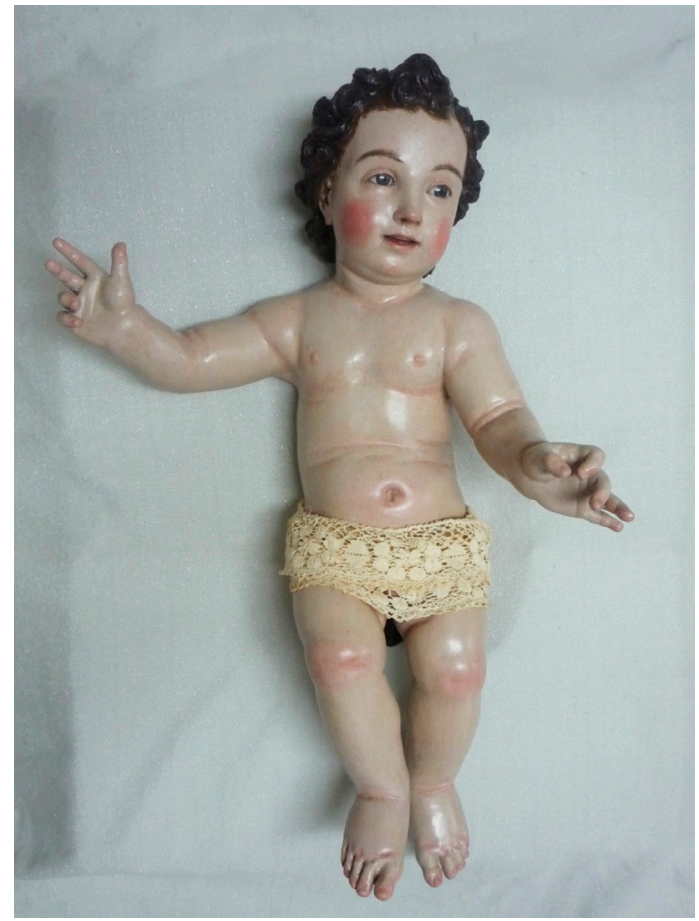

Anónimo. Niño Jesús del Carmen. Convento del Santo Ángel, Sevilla, s. XVIII. hechuras de dos niños jesuses de piedra de guamanga dentro y dos agelitos y otros dos hechuras de niños desuses chiquitos y un papel dentro de dha cajetilla que dice es de nuestra sra del buen suceso». ${ }^{88}$

No podemos olvidar en este rápido repaso las obras de marfil, muy habituales en los espacios privados porque los propios artífices locales aprendieron a trabajarlo. Poco aclaran las fuentes en relación con la procedencia de este tipo de obras, como ocurre con el inventario del contador mayor José de Caviedes, escriturado en abril de 1653, donde se alude a «vna echura de un santo xpto de bulto de gueso» ${ }^{89}$. Es posible que en su caso fuera una obra viajera.

Esta tímida intromisión en los hogares y talleres sevillanos me ha dado noticias sobre un capítulo en la historia del arte sevillano muy importante y sólo parcialmente

88 Laureano Gelder recibió los bienes del benefactor y los llevó a destino. Ochoa recuerda en el documento firmado al efecto, con unas de las prendas entregadas, «un salero dorado sin tapa», que destinaba «para la pila de la iglesia mayor de Valderas, donde se bautizó Gaspar Ochoa». AHPS, 3715, fol. 739vto [739740; 8-V-1668. A Ochoa se le documenta como rector de la Universidad de San Marcos 1644. Catálogo de Cofradías del Archivo del Arzobispado de Lima, El Escorial, Instituto Escurialense de Investigaciones Históricas y Artístias, 2014, doc. 597, p. 119.

89 AHPS, 3685, fol. 622vto. Otra referencia similar entre los bienes de doña Eufrasia Cortés, doncella: «Yten un santo xpto pequeño de gruesso (¿gueso?)». AHPS, 540, 1649, fol. 212vto. 
analizado, el del consumo privado de obras de arte. No es la primera vez que me intereso por esta vertiente de la demanda artística, bien que antes de ahora lo he hecho en relación con la creación pictórica, que sin embargo tiene mucho en común con lo visto en el presente estudio.

Hablar de consumo artístico es aludir a las relaciones entre creadores y clientes en un sentido amplio, en las que sin negar la importancia del impulso religioso o devocional, hay que ponderar los gustos personales, las necesidades particulares o los usos y costumbres hogareños. Al fin la obra de arte funciona como objeto con un significado que permite conocer mejor a la sociedad y las circunstancias en que se desenvuelve. Y quizás nada mejor que poner la atención en la producción de los talleres sevillanos a partir de la crisis del cuarenta y nueve, que hubieron de mostrar su capacidad de respuesta ante tan adversa coyuntura. Una coyuntura que igualmente afectó a la demanda, cuyos cambios de sensiblidad fueron notorios. 


\section{BIBLIOGRAFÍA}

Alcalá, L. E. «...Fatiga, y cuidados, y gastos, y regalos...: Aspectos de la circulación de la escultura napolitana a ambos lados del Atlántico», Libros de la Corte, 5, 2017, pp. 163-184.

Amador Marrero, P. F., Imaginería ligera nohovispana en el arte español de los siglos XVI-XVII. Tesis doctoral defendida en Universidad de las Palmas, 2012, en repositorio de la Universidad.

Baudrillart, J. La sociedad de consumo. Sus mitos, sus estructuras, Madrid, Siglo XXI, 2009.

Brewer, John, Poter, Roy, Consumption and the World of Goods, Abingdom, Routledge, 1993.

Bruquetas Galán, R., «Los gremios, las ordenanzas, los obradores», In Gabaldo García, A. y Ineba Tamarit, P., dirs., La pintura europea sobre tabla, siglos XV, XVI y XVII, Madrid, Ministerio de Cultura, 2010.

Catálogo de Cofradías del Archivo del Arzobispado de Lima, El Escorial, Instituto Escurialense de Investigaciones Históricas y Artístias, 2014.

De Otazu, A. y Díaz de Durana, J. R., El espíritu emprendedor de los vascos, Madrid, Sílex, 2008.

De Bago y Quintanilla, M., Hernández y Díaz, J. y Sancho Corbacho, H., Documentos para la Historia del Arte en Andalucía, Sevilla, 1928.

De Vries, Jan, The Industrious Revolution, Consumer Behavior and the household Economy 1650 to the Present, Cambridge, Cambridge University Press, 2008.

Di Lustro, A., Gli scultori Gaetano e Pietro Patalano, tra Napoli e Cadice. Nápoles, Arte tipográfica, 1993.

Espinosa de los Monteros Sánchez, F., «Nuevas aportaciones a las vidas y obras de Ignacio Francisco López y Alonso de Morales», Revista de Historia de El Puerto, 42, 2009, pp. 63-83.

Estrada Jasso, A., Imágenes en Caña de Maíz, San Luis de Potosí, Universidad Autónoma, 1996.

Falcón Márquez, T., «El arquitecto de retablos y escultor Martín Moreno y los primeros retablos con columnas salomónicas en Sevilla», Boletín de Arte, 34, 2013, p. 69-87.

García Fuentes, L., Los peruleros y el comercio de Sevilla con las Indias, 1580-1630. Sevilla, Universidad, 1997.

García Olloqui, M. V., «La iconografía de «La Natividad» en la obra de La Roldana. El problema de los belenes atribuidos. Diferencias, estudio estilítico y opiniones cualificadas», Fuentes, 1, 1998, s. p.

Gestoso y Pérez, J., Ensayo de un diccionario de los artífices que florecieron en Sevilla. Desde el siglo XIII al XVIII inclusives, Sevilla, Oficina de la Andalucía Moderna, 1899.

Gila Medina, L. y Herrera García, F. J., coords. El triunfo del barroco en la escultura andaluza e hispanoamericana, Granada, EUG., 2018. 
Hernández Díaz, J., Juan Martínez Montañes (1568-1649), Sevilla, Guadalquivir, 1987. Iglesias Castellano, A., «El ciego callejero en la España Moderna: balance y propuestas», LaborHistórico, 2/1, 2016, pp. 74-90.

López Jiménez, J. C., «Escultura barroca italiana en Levante y Sur de España», Boletín de la Real Academia de Córdoba de Ciencias, Bellas Letras y Nobles Artes de Córdoba, 85, 1963, pp. 76-124.

López Martínez, C., Desde Jerónimo Hernández hasta Martínez Montañes. Notas para la Historia del Arte, Sevilla, Tipografía Rodríguez, 1932.

Luján López, F. B., «Nuestra Señora de Copacabana, una devoción andina patrona de Rubielos Altos (Cuenca). Su origen y difusión», Revista Murciana de Antropología, 8, 2002, pp. 193-246.

Maquívar, M. del C., «Los 'adornadores del Credo Divino': Imagineros barrocos novohispanos», III CIBI, Universidad Pablo de Olavide, Sevilla, pp. 467-480.

Martínez Lara, P. M., «Sedimento material de una vida humanista. El inventario de bienes de Pablo de Céspedes», Boletín de Arte, 32-33, 2011-2012, p. 437-455.

Martínez Lara, P. M. y de la Torre Amerighi, I., «Una escultura desconocida de Cristóbal Ramos (1725-1799). Iconografía, uso artístico y mentalidad ilustrada a propósito de una imagen de San José con el Niño», Liño. Revista Anual de Historia del Arte, 23, 2017, pp. 57-68.

McKendrick, Neil et al., The Birth of a Consumer Society, Londres, 1982.

Moreno Arana, J. M., «La difusión del barroquismo sevillano en El Puerto y su entorno: Ignacio López y Alonso de Morales y su retablo de Ánimas de La Prioral (s. XVIIXVIII)», Revista de Historia de El Puerto, 37, 2006, pp. 47-80.

Pacheco, F., El Arte de la Pintura, ed. B. Bassegoda, Madrid, Cátedra, 1990,

Palomero Páramo, J. M., «Notas sobre el taller de Zurbarán. Un envío de lienzos a Portobelo y Lima», in García, S., ed., Extremadura en la evangelización del Nuevo Mundo, Madrid, Sociedad Estatal Quinto Centenario, 1990, pp. 313-330.

Peña Martín, Á., «La circulación de modelos escultóricos en el territorio de la Monarquía Hispánica: el Niño Jesús dormido sobre la cruz y calavera del taller de Martínez Montañés», Copia e invención. Modelos, réplicas, series y citas en la escultura europea, Valladolid, Museo Nacional de Escultura, 2013, pp. 297-311.

Porres Benavides, J., «El comercio de imágenes devocionales con América y la producción seriada de los talleres escultóricos sevillanos». Ucoarte, 2, 2013, pp. 9-16

Porres Benavides, J., «Escultores y esculturas en el Virreinato de Perú a comienzos del Barroco», Revista del Instituto Riva-Agüero, 3/2, 2018, p. 171-202.

Prado-Campos, B., «Imaginería ligera. Un barroco al servicio de la colonización», In Fernández Paradas, A. R., aut., Escultura barroca española: nueva lecturas desde los siglos de oro a la sociedad del conocimiento, Antequera, Exlibric, 2016, vol. 1, pp. 151-170.

Quiles, F., «Abril para morircolecciones artísticas sevillanas en el año de la peste (1649)», In López Calderón, C., Fernández Valles, Mª de los y Rodríguez Moya, I., coords., 
Barroco iberoamericano: Identidades de un imperio, Santiago de Compostela, Andavira, 2013, vol. 2, pp. 257-273.

Quiles, F., Sevilla y América en el Barroco. Comercio, ciudad y arte, Sevilla, Bosque de Palabras, 2009, p. 84.

Quiles, F., «Hijos de la mar y comerciantes de Indias. Bienes artísticos en casa de los Cruzelaegui (Sevilla, m. XVII)», Cuadernos de los Amigos de los Museos de Osuna, 21, 2019, pp. 58-62.

Ramírez Montes, G., Catálogo de documentos de arte en el Archivo General de Indias, México, UNAM, 1983.

Real Palma, Ma . T., dir., Memoria Final de Intervención. Crucificado del Capítulo. Iglesia de Santo Domingo de Guzmán, Bornos, Cádiz. Septiembre de 2013. Edita IAPH, Consejería de Cultura, 2013.

Roda Peña, J., «Los bienes artísticos de Diego de Paiva, un comerciantes portugués en la Sevilla del siglo XVII», Atrio, 13-14, 2007-2008, pp. 127-160.

Roda Peña, J., «La escultura sevillana del pleno barroco y sus protagonistas durante la segunda mitad del siglo XVII», in Gila Medina, L. y Herrera García, F. J., coords. El triunfo del barroco en la escultura andaluza e hispanoamericana, Granada, Universidad, 2018, pp. 229-266.

Sánchez Sánchez, J. Mª ., «Los obradores artísticos sevillanos del siglo XVI. Adaptaciones y cambios para satisfacer los encargos del mercado americano». Anales del Instituto de Investigaciones Estéticas, XXXV/103, 2013, pp. 177-196.

Trentman, Frank, ed., The Oxford Handbook of the History of Consumption, Oxford-New York, Oxford University Press, 2012.

Urrea, J., «Introducción a la escultura barroca madrileña. Manuel Pereira», BSAA, 43, 1977, pp. 253-268.

Valiñas López, F. M., «El belén ante la historia del arte. Apuntes para el estudio de sus elementos contenidos escenográficos». Cuadernos de Arte de Granada, 40, 2009, pp. 415-432.

Vila Vilar, E., «Las ferias de Portobelo: Apriencia y realidad del comercio con Indias». Anuario de Estudios Americanos, XXXIX, 1982, pp. 275-340.

Vila Vilar, E., «Los maestres de plata: Un resorte de poder en el comercio de Indias», in Sarabia Viejo, M. J., Ortiz de la Tabla, J., Pérez-Mallaína, P. E., Hernández Palomo, eds. Entre Puebla de los Ángeles y Sevilla. Homenaje al Dr. José Antonio Calderón Quijano, Sevilla, Universidad, 1997, pp. 119-132.

Vilela Gallego, P., Catálogo de los documentos del Archivo de los Condes de Gómara y familia Arias de Saavedra, Sevilla, Consejería de Cultura, 2009.

Wuffarden, L. E. y Guibovich, P., «El clérigo Juan López de Vozmediano, comitente de Martínez Montañés en Lima», BIRA, 17, 1990, 419-430.

Yun Casalilla, Bartolomé, Aram, Bethany, Global goods and the Spanish Empire, 14921824: circulation, resistance and diversity, Houndmills, Palgrave Macmillan, 2014. 